\title{
LA IMPRONTA DEL CONSTITUCIONALISMO GADITANO EN LA INDEPENDENCIA DEL REINO DE GUATEMALA, 1810-1821
}

\section{THE IMPRINT OF GADITAN CONSTITUTIONALISM IN INDEPENDENCE OF THE KINGDOM OF GUATEMALA, 1810-1821}

\author{
Arturo Taracena Arriola \\ CEPHCIS-UNAM \\ Juan Carlos Sarazúa Pérez \\ CEM-IIFL-UNAM
}

\begin{abstract}
SUMARIO: I. LOS INICIOS.- II. LOS INICIOS DE LA COYUNTURA GADITANA EN EL REINO DE GUATEMALA.- III. LAS INSTRUCCIONES GUATEMALTECAS.- IV. LABOR PARLAMENTARIA DE ANTONIO DE LARRAZÁBAL Y FLORENCIO DEL CASTILLO.- V. LA LABOR PARLAMENTARIA DE LOS HERMANOS DEL LLANO.VI. LA REACCIÓN ABSOLUTISTA DEL CAPITÁN GENERAL BUSTAMANTE Y GUERRA.- VII. DESTINO FINAL DEL DIPUTADO LARRAZÁBAL Y DE LOS DOCUMENTOS GUATEMALTECOS.- VIII. LA REBELIÓN DE RIEGO Y EL INICIO DE LA COYUNTURA INDEPENDENTISTA.- IX. LA ELECCIÓN DE DIPUTADOS A CORTES EN 1820.- X. LA DIPUTACIÓN PROVINCIAL DE GUATEMALA Y LA JUNTA PROVINCIAL CONSULTIVA DEL REINO.- XI. LAS DIFICULTADES DE APLICACIÓN DEL ESPÍRITU GADITANO.- XII. EL DEBATE EN LA PRENSA.- XIII. LA INDEPENDENCIA DE ESPAÑA.-
\end{abstract}

Resumen: El artículo se enfoca en el impacto del debate constitucional en la independencia en Centroamérica, por medio de las publicaciones surgidas con la libertad de imprenta y las solicitudes de reformas por parte de los diputados en las Cortes. La coyuntura politica abierta con los acontecimientos en 1808, llevaron a una serie de propuestas de reformas en la forma de gobernar al interior de la Monarquía Española que ayudaran a mantener la unidad política durante la crisis. Sin embargo, a nivel local, el debate sobre las implicaciones de una constitución escrita fue la base para el reclamo de las elites americanas ante las autoridades reales en el Reino y las Cortes. Dar seguimiento al debate constitucional permitirá discutir aspectos centrales de la independencia en Centroamérica.

Abstract: The article focuses on the impact of the constitutional debate on independence in Central America, through the publications that emerged with the freedom of the press and the requests for reforms by the deputies in the Cortes. The political conjuncture opened with the events in 1808 , led to a series of reform proposals in the way of governing within the Spanish Monarchy that would help maintain political unity during the crisis. However, at the local level, the debate on the implications of a written constitution was the basis for the claim of the American elites before the royal authorities in the Kingdom and the Cortes. 
Following up on the constitutional debate will allow the discussion of central aspects of independence in Central America.

Palabras clave: Cortés de Cádiz, constitucionalismo, Monarquía, Centroamérica, independencias.

Keywords: Cortés de Cádiz, constitutionalism, Monarchy, Central America, independence.

\section{LOS INICIOS 1}

Las noticias de la formación de una Junta Central a raíz de haber sido hecho prisionero Fernando VII por los franceses en Bayona llegó a Guatemala el 14 de agosto de 1808. El Ayuntamiento de la Nueva Guatemala dirigió el 23 de agosto una carta al capitán general Antonio González y Saravia en la que le manifestaba su derecho a decidir sobre la mejor manera de servir al nuevo rey, José Bonaparte. Luego, el 15 de noviembre pidió tener representatividad en cualquier tipo de gobierno que se organizara en España. De esa forma, en mayo de 1809, el Reino de Guatemala dio inicio al proceso para elegir un representante ante la Junta Central Suprema y Gubernativa. De esa primera elección salió elegido representante el comerciante y regidor Manuel Pavón, quien no llegó a viajar a la Península.

Cuando la Junta Central, a principios de 1810, emitió la convocatoria para integrar la Constituyente de Cádiz, la información tardó varios meses en llegar al Reino de Guatemala, pues solamente se conoció dicha noticia hasta el mes de junio. A partir de esta fecha, se dio inicio entre las autoridades guatemaltecas una febril actividad para enviar diputados "debidamente instruidos" a defender los intereses del Reino en las Cortes gaditanas, que fueron inauguradas el 24 de septiembre de ese año.

Esta coyuntura histórica y el proceso político que lo acompañó marcarian el inicio del fin del Antiguo Régimen, aunque elementos de éste habrian de prolongarse en el istmo hasta las revoluciones liberales de la década de 1870. Asimismo, fue el comienzo del constitucionalismo en Centroamérica, tanto por la formulación de un Proyecto Constitucional elaborada por el Ayuntamiento de la Ciudad de Guatemala como por la adopción de la Constitución de Cádiz de 1812, que establecía la monarquía parlamentaria y que incluyó algunas de las propuestas de los diputados centroamericanos. Documentos que tendrían una influencia directa en las posteriores constituciones del istmo.

1 Véase: Mario Rodríguez, El experimento de Cádiz en Centroamérica , 1808-1826, México, Fondo de cultura Económica, 1984; Jorge Mario García Laguardia, Centroamérica en las Cortes de Cádiz, México, Fondo de cultura Económica, 1994; Manuel Chust, La cuestión nacional americana en las cortes de Cádiz (1810-1814), Valencia Artes Gráficas Soler, 1999; Jordana Dym, "Soberanía transitiva y adhesión condicional: lealtad e insurrección en el Reino de Guatemala, 1808-1811" en Araucaria: Revista Iberoamericana de Filosofia, Politica, Humanidades y Relaciones Internacionales, Vol. 9, $\mathrm{N}^{\circ}$ 18, 2007, págs. 196-219; David Diaz Arias y Ronny Viales Hurtado (recopiladores), Independencia, estados y Politica(s) en la Centroamérica del siglo XIX: las huellas del bicentenario, San José Centro de Investigaciones Históricas de América Central/UCR, 2012; Manuel Benavides Barquero, "Las Cortes de Cádiz: eslabón perdido de la historiografia centroamericana" en Cuadernos Americanos No 155, México, 2018/4, pp. 11-42. 
Normalmente, se hace especial mención a las destacadas intervenciones de dos de los diputados a esas primeras Cortes de Cádiz, el canónigo Antonio Larrazábal y el presbítero Florencio del Castillo. En las Cortes se evidenció que la participación del Reino de Guatemala estaba impregnada de intervenciones en favor de las provincias que lo integraban y de los intereses particulares de sus propias élites; asimismo, del Reino frente a España; y, en mucho menor medida, en favor de la Nación española.

La razón de la primera situación eran las diferencias históricas que marcaba la complicada geografia del istmo centroamericano, tironeado entre los intereses de la Nueva España y los de Panamá, perteneciente a la Nueva Granada. Respecto a la segunda, sobresalía la posición de los criollos americanos frente a la metrópoli, que, si bien ésta tenía una tónica general en defensa del poder de sus élites, estaba influenciada por las evidentes diferencias que se daban entre los diversos Reinos y aquellas existentes en el seno de cada uno de ellos, como era el caso para las provincias guatemaltecas la "opresión" ejercida por las autoridades y comerciantes de la Nueva Guatemala. Finalmente, en cuanto al tercer considerando, se tomaban en cuenta los trescientos años de pertenecía de sus élites al funcionamiento político y económico de España y a la necesidad de preservar los intereses del Imperio español frente a los embates comerciales y militares de los imperios inglés y francés.

A ello hay que agregar que la impronta del sistema de Intendencias establecido en la segunda mitad del siglo XVIII y su lógica autonómica arraigó las diferencias entre las provincias guatemaltecas, las cuales se vieron reflejadas en las propuestas presentadas en Cádiz por los diputados electos por cada una de ellas. De hecho, las cuatro intendencias establecidas en el Reino (Chiapas, San Salvador, Honduras y Nicaragua-Costa Rica) rompieron su unidad efectiva, sobre todo por la incapacidad de la élite de la Nueva Guatemala para hacer alianzas económicas y sociales con las élites provinciales, las que con el tiempo ayudasen a contener la cada vez más evidente dinámica fragmentadora del territorio.

Como ha subrayado Benavides Barquero (2018), con sus variantes y diferencias, los diputados americanos incidieron en la redacción de la Constitución gaditana de 1812, así como en las demás leyes en todo aquello que estuvieron de acuerdo con los diputados españoles. De hecho, el logro global de los diputados americanos a Cortes fue contribuir a fijar las atribuciones propias de los ayuntamientos constitucionales y las diputaciones provinciales

\section{LOS INICIOS DE LA COYUNTURA GADITANA EN EL REINO DE GUATEMALA}

La discusión sobre la igualdad de la representación americana y española en la Cortes de Cádiz se vio perturbada en el Reino de Guatemala a partir de que el capitán general González y Saravia hiciese conocer el decreto relativo a elegir diputados a Cortes y el Manifiesto del Supremo Consejo de Regencia a los españoles americanos, fechado en Real Isla de León, 14 de febrero de 1810. E1 Ayuntamiento de la Nueva Guatemala se apresuró a cumplir con lo ordenado y se reunió el 24 de julio para proceder a la elección del diputado por la capital. En la terna presentada salió favorecido el canónigo Antonio Larrazábal (1769-1853), quien era vicario capitular y gobernador del Arzobispado del Reino. 
Paralelamente, el capitán general cursó el decreto a las diversas provincias y, realizadas las elecciones, salieron a su vez designados los siguientes diputados: por Chiapas: licenciado Sebastián Esponda, quien por haber fallecido fue sustituido por el sacerdote y secretario del obispado, Mariano Robles Dominguez; por San Salvador, Ignacio Ávila; por Honduras: el abogado Francisco Morejón; por Nicaragua: Juan Francisco Vilches, sustituido al renunciar por el abogado de la Real Audiencia, José Antonio López de la Plata; y Por Costa Rica: Nicolás Carrillo, sustituido al renunciar por el presbítero Florencio del Castillo. Finalmente, por el distrito de Santiago de Guatemala, Andrés de Llano Nájera, capitán de Navío retirado de la Real Armada, quien pasó a ser suplente tras la llegada del diputado titular. Tanto Larrazábal como Del Castillo llegaron a ser presidentes de las Cortes gaditanas.

Debido a la dificultad para que los diputados americanos electos llegasen a Cádiz, se optó por nombrar diputados suplentes, escogidos entre los oriundos de esas provincias que residian en la Península. Así, por Guatemala resultaron electos los hermanos Andrés y Manuel del Llano -militares ambos-, quienes, siendo hijos de un funcionario español con cargo de Contador Real, habían nacido en este Reino, pero que por razones domésticas y profesionales vivian en Cádiz en el momento de su elección.

\section{LAS INSTRUCCIONES GUATEMALTECAS ${ }^{2}$}

En la contribución documental del Ayuntamiento de Guatemala para que Larrazábal desempeñase su cargo sobresalen Las Instrucciones para la Constitución fundamental de la Monarquía Española..., elaboradas por José María Peinado (1770-1820), con el auxilio de regidor Antonio José Juarros (1774-1714) y del licenciado nicaragüense Miguel de Larreynaga (1772-1847), las que fueron aprobadas por los diferentes ayuntamientos de las provincias y, seguidamente enviadas a Larrazabal, quien las hizo imprimir en Cádiz el año de 1811.3

García Laguardia considera que los principales aportes de las Instrucciones a las ideas e instituciones politicas se centraron en las claras limitaciones planteadas a la Monarquía absoluta, influenciadas tanto por la crítica al despotismo por parte de la Constitución francesa de 1794 como por los debates y escritos españoles durante la etapa previa a la inauguración de las Cortes. Es decir, "reconociendo los derechos del hombre y estableciendo un sistema de competencias circunscritas en las que se dividiría el poder". Asimismo, en éstas estaba presente la influencia del Espíritu de las leyes (1748) del barón

2 Jorge Mario García Laguardia, Génesis del Constitucionalismo guatemalteco, Guatemala, Editorial Universitaria, 1971; Adriana Álvarez Sánchez. "La Real Universidad de San Carlos de Guatemala frente al proceso de In- dependencia (1808-1815) en XIV Encuentro de Latinoamericanistas Españoles: congreso internacional, Santiago de Compostela, España. Septiembre de 2010, pp.489-508.

${ }^{3}$ Instrucciones/ para/ la constitución fundamental/ de la Monarquia Española/ y su Gobierno/ de que ha de tratarse en las próximas cortes generales/ de la Nación/ Dadas por el M. I. Ayuntamiento/ de la M. N. y L. Ciudad de Guatemala/ a su Diputado el Sr. D. Antonio Larrazabal/ Canónigo Penitenciario de esta Sta. Iglesia metropolitana/ formadas por el Sr. José María Peinado, regidos per/ petuo y decano del mismo Ayuntamiento/ Las da a luz en la ciudad de Cádiz el referido/ diputado. En la Imprenta de la Junta Superior. Año de 1811; 
Montesquieu en torno a las formas de gobierno. La Monarquía española lo centraba en un solo individuo, sin normas claras de control. Para paliar tal despotismo, el Ayuntamiento guatemalteco proponía en las Instrucciones la promulgación de una constitución que previniese el ejercido por el

jefe de la Nación; que señale los limites de su autoridad, que haga del Rey un padre y un ciudadano que establezca una leyes consultadas con el derecho natural, que contiene en sí todas las reglas de lo equitativo y los justo, y que se hallen revestidos en todos los caracteres de la bondad absoluta, y de la bondad relativa a los objetos primarios de la sociedad: que enseñen a los pueblos sus deberes: que circunscriban sus obligaciones: y que a éstas y a sus derechos señalen límites fijos e inalterables: que establezca una administración clara, sencilla y cimentada en los principios de propiedad, libertad y seguridad. 4

Seguidamente, las Instrucciones pasaban a proponer una Declaración de los Derechos del ciudadano inspirada en la que estaba incluida en la Constitutión de la République Française de 1794, aprobada al año siguiente. haciendo una enumeración de 30 derechos, entre los cuales sobresalían con insistencia los relativos a la defensa de $: 4^{\circ}$ de la ciudadana de "igualdad, la propiedad, la seguridad y la libertad"; $7^{\circ}$ que "la justicia natural se viola cuando una parte de la nación pretende privar a la otra del uso de sus derechos"; $15^{\circ}$, que "la garantía social consiste en la acción de todo para asegurar a cada uno en el goce y conservación de sus derechos"; y 22을 "la nación española en toda su actual extensión es una e indivisible, y todos sus individuos deben gozar de sus derechos naturales en toda su plenitud".

A continuación, el documento del Ayuntamiento incluía un Proyecto de Constitución compuesto por 112 artículos, siendo el primer proyecto constitucional elaborado en la historia guatemalteca y centroamericana. Su eje jurídico era el abandono del sistema clásico de monarquía absoluta, basado en la teoría del derecho divino del monarca, optando por la fórmula de una monarquía constitucional, cuyos artículos $20^{\circ}$,"el soberano tendrá la facultad ejecutiva, y la nación la legislativa" y 21 "aunque jefe supremo de la justicia, no podrá juzgar por sí mismo, sino por medio de magistrados, que lo harán con arreglo a las leyes, y no podrán ser removidos, si no es por sentencia pronunciada en juicio a que den mérito", acotaban la autoridad real subrayando la independencia de la justicia. Una propuesta que se vería reforzada más adelante por el apartado Discurso sobre la reforma de algunas leyes en el que se insistía en señalar que la elaboración de leyes debía de hacerse tomando en cuenta "la dulzura de la religión, que profesamos" [la católica], "la equidad o derecho natural" y "la experiencia de los siglos pasados", que obligaba a abolir aquellas leyes que mantuviesen el espíritu del absolutismo. ${ }^{5}$

Al mismo tiempo, el Proyecto de Constitución proponía en el artículo 39 la creación de un Consejo Supremo Nacional "en el que residirá toda la representación de la Nación española y tendrá el Poder Legislativo en toda su extensión de los Códigos civil y criminal, político y económico". Es decir, defendia

4 "Instrucciones para la Constitución Fundamental de la Monarquía Española y su Gobierno de que ha de tratarse en las próximas cortes generales de la Nación", en García Laguardia, Génesis del Constitucionalismo guatemalteco, Guatemala, Editorial Universitaria, 1971, pp. 112-113.

5 “Instrucciones para la Constitución Fundamental...", pp. 187-189. 
la idea de un sistema de descentralización, el cual se haría efectivo a través de juntas locales en cada capital del Reino.

Por último, el Proyecto constitucional guatemalteco opinaba sobre el Sistema Económico defendiendo la libertad de comercio frente a las propuestas de la minoria de los regidores que sustentaba el proteccionismo y el mercantilismo. Reconocía que las ideas de Adam Smith influian en sus peticiones en materia de abolición de los estancos, gabelas y tributos, y en las restricciones a la actividad mercantil. Exigía, en el apartado Proyecto de una Contribución, la idea de un impuesto único y la necesidad de hacer un censo completo de la población del Reino de Guatemala, que permitiese fijar los parámetros de elección de diputados por cada una de sus provincias. A su vez, incluía una reforma al financiamiento del clero, proponiendo que se redujeran los cobros por actos religiosos y que, en vez de diezmos, se les proporcionara un ingreso fijo a partir de fondos públicos. Las múltiples consideraciones de orden económico y fiscal demostraban el interés de la élite criolla capitalina por nuevas reformas en favor de sus intereses como americanos, aunque no necesariamente en favor de las élites de las provincias, que estaban sujetas a su monopolio mercantil y administrativo. ${ }^{6}$

Obviamente, tal propuesta, que se consideraba como progresista y liberal, no hizo unanimidad entre los miembros del Ayuntamiento de la Ciudad de Guatemala, por lo que cuatro regidores (José de Isasi, Sebastián Melón, Miguel González y Juan Antonio de Aqueche) se abstuvieron de ratificarlo. Su voto razonado fue expuesto en el documento intitulado Apuntes Instructivos. ${ }^{7}$ Como grupo de comerciantes peninsulares en el cuerpo municipal capitalino sostenian que al Reino de Guatemala le convenía más adoptar el espíritu moderado de la Constitución inglesa, lo que implicaba no limitar la autoridad real, como la mayoría de sus pares lo requería. Sin embargo, apoyaban los principios de la división de poderes y de la soberanía nacional, este último fundado en Contrato social (1762) de Jean Jacques Rousseau, como lo advirtió el Dictamen del Consejo de Indias sobre las Instrucciones a Larrazábal de 28 de febrero de 1817.

Asimismo, el Consulado de Comercio formuló unos Apuntamientos sobre la Agricultura y Comercio del Reyno de Guatemala 8 para apoyar el desempeño de Larrazábal a fin de que tuviese elementos concretos de análisis sobre la realidad de este territorio americano. Estos constituían la radiografia más completa de la estructura social y económica del Reino en los albores del siglo XIX. En ellos se sostenía que el latifundio era la principal causa de su atraso y que la tierra comunal debía de distribuirse en propiedad privada, pues era necesario restituir las tierras que los españoles habian hecho suyas en agravio de los indígenas y poner fin al repartimiento de indios, que solamente favorecía el enriquecimiento

6 “Instrucciones para la Constitución Fundamental...", pp. 141-163.

7 Apuntes Instructivos/ que/ al Señor Don Antonio Larrazabal/ DIPUTADO/ a las Cortes Extraordinarias/ de la Nación Española/ por el Cabildo/ de la Ciudad de Guatemala/ dieron sus regidores/ Don José de Isasi, Don Sebastián Melón, / Don Manuel González y Don Juan Antonio/ de Aqueche./ NUEVA GUATEMALA/ Impreso en la Oficina de D. Manuel de Arévalo./ Año de 1811.

8 Apuntamientos/ sobre/ la Agricultura y Comercio/ del/ Reyno de Guatemala/ que/ el Señor Dr. Don Antonio Larrazabal/ Diputado en las Cortes Extraordinarias/ de la Nación/ por las misma Ciudad/ pidió al Real Consulado/ en/ Junta de Gobierno de 20 de Octubre/ de 1810/ Nueva Guatemala./ Impreso en la Oficina de D. Manuel de Arévalo. Año de 1811. 
de los funcionarios públicos. Por ello, convenía repartir ejidos y tierras baldias a las castas (ladinos y pardos), favoreciendo la idea de un ciudadano propietario.

Finalmente, Larrazábal, quien había sido rector de la Pontificia Universidad de San Carlos en 1805, a petición suya en carta del 12 de octubre de 1810, contó con el asesoramiento del claustro de profesores. Un mes después, éste se acordó remitir los poderes a España no sólo dirigidos al diputado Larrazábal, sino también a los diputados suplentes que habían sido elegidos en 1810, el licenciado José Antonio López de la Plata, el salvadoreño José Ignacio Ávila y el chiapaneco Mariano Robles. A su vez, convino en señalar los dias 26 y 27 de septiembre de 1812 para realizar el juramento de la Constitución gaditana y, en marzo de 1813, asimismo, que en la Cátedra Prima de Leyes se la estudiara con el propósito de formar a los nuevos abogados y jueces en su espíritu. Cuando en 1820, la Constitución fue reestablecida, Larrazábal fue electo nuevamente rector de la Universidad.

La ceremonia pública de jura se llevó a cabo el 28 de septiembre bajo la presidencia de Bustamante y Guerra. Para acompañarla, el Ayuntamiento de la ciudad de Guatemala tomó la decisión de acuñar en la Casa de Moneda medallas de plata y oro en su honor, con la inscripción en el anverso "Guatemala, 24 de septiembre de 1812" y en el reverso "Por la Constitución Política de las Españas", sobresaliendo el hecho de que, en el libro constitucional abierto se lee "Justicia" y "Equidad, evidenciando el mensaje político a las Cortes por parte del Ayuntamiento guatemalteco. De la medalla se mandaron a hacer 2000 piezas de plata y 300 de oro. En la ciudad de San Salvador, la jura se realizó el 8 de octubre. ${ }^{9}$

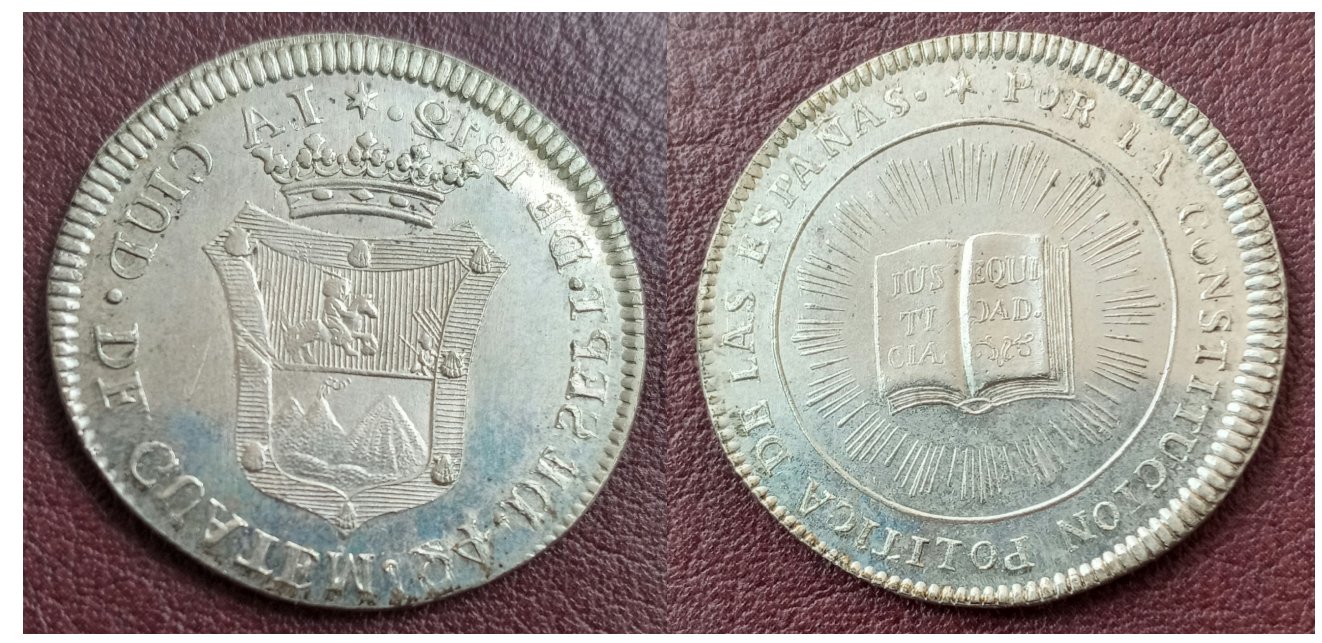

Medalla de Jura de la Constitución de 1812, Nueva Guatemala Colección Edgardo Barreda, Guatemala

El nuevo capitán general José Bustamante y Guerra (1759-1825), quien había tomado posesión en marzo de 1811, hizo un análisis certero de las

9 J. Roberto Jovel, Medallas de proclama de los reyes de España usadas como monedas en Centroamérica, San Salvador, Imprenta y Offset Ricaldone, 2013, 127-135. 
aspiraciones de la élite criolla de la capital del Reino al anotar en el ejemplar de las Instrucciones que envió a España, las siguientes consideraciones:

Esta es la Constitución del Ayuntamiento de Guatemala, que de tiempo inmemorial ha estado estancado en las familias de los americanos que la firman. De ella resulta que en sus artículos se deprime la autoridad del rey, se exalta la de los Ayuntamientos; que los Ayuntamientos son los que debian nombrar a los individuos de las Juntas serenísimas en quienes debían residir el gobierno de cada provincia en todos sus ramos y el derecho de informar para la provisión de empleos; que los Ayuntamientos debían hacer la elección de los individuos del Consejo Supremo Nacional en el que debía estar el Poder Legislativo, Ejecutivo y de dar todos los empleos políticos, militares y eclesiásticos; que los Ayuntamientos de América, mayores en número que los de España, eran, por consecuencia, el centro de las autoridades que habian de dictar leyes, proveer los empleos, gobernar la Monarquía y administrar las provincias; que a este respecto la soberanía quedaba realmente en la América cuando su situación era tan crítica... ${ }^{10}$

\section{LABOR PARLAMENTARIA DE ANTONIO DE LARRAZÁBAL Y FLORENCIO DEL CASTILLO. 11}

Los diputados centroamericanos, como muchos de los otros americanos, buscaron resolver situaciones económicas, politicas y sociales de sus diversas realidades. De esa forma, mientras Del Castillo o Robles estaban preocupados por las provincias de Costa Rica y Chiapas respectivamente, Larrazábal hablaba desde los intereses de la élite criolla del Reino, establecida en la ciudad de la Nueva Guatemala. Es decir, en Cádiz los propios centroamericanos expusieron abiertamente sus diferencias económicas, politicas y sociales.

Tres meses después de su elección, el canónigo Larrazábal juró su cargo en esa ciudad el 24 de agosto de 1811. Desde ésta mantuvo una permanente comunicación con el ayuntamiento guatemalteco a raíz de las instrucciones precisas que le había girado $\mathrm{y}$, a su vez, desempeñó cargos importantes en las Cortes. Participó en las Comisiones de Honor, Ultramarina, Seminario de Canarias, Justicia, Asuntos Eclesiásticos y, además, fue miembro de la Diputación Permanente al ser electo por unanimidad y, finalmente, fungió como presidente de las Cortes.

Su participación en la discusión del proyecto de Constitución fue de lo más destacado, incluyendo una gran variedad de asuntos relacionados con la organización general de la nueva monarquía constitucional española, la de los asuntos propiamente americanos, así como los de su propio Reino y provincia, además de los relativos a la organización religiosa. De esa forma, participó en discusión sobre la limitación de las facultades del Rey, el reglamento del Poder Ejecutivo, el reemplazo del Consejo de Estado, las proposiciones sobre régimen electoral, la administración de justicia, la defensa de la libertad de imprenta, la forma de gobierno de las provincias -impulsando la descentralización por medio

10 "C. G. Bustamante al Consejo de Indias, 3 de septiembre de 1811 " en Jordana Dym, Soberanía transitiva y adhesión condicional..., Nota 37, p. 208.

11 El principal estudio biográfico de Larrazabal es obra de César Brañas, José Antonio de Larrazabal, un guatemalteco en la historia, Guatemala, Editorial Universitaria, 1969 y el de Del Castillo del padre Manuel Benavides Barquero, El presbitero Florencio del Castillo. Diputado por Costa Rica en las Cortes de Cádiz, san José de Costa Rica, Editorial LIL, 2010. 
de las diputaciones provinciales y la autonomía municipal-, la libertad económica -especialmente la libertad del comercio ultramarino y la supresión de estancos y monopolios-, la defensa del fuero religioso y otras varias reivindicaciones de la Iglesia. Asimismo, en la defensa de los derechos de prisioneros, la necesidad de derechos políticos para las castas, la defensa de los indios, proponiendo la abolición de las mitas en apoyo a lo defendido con vehemencia por su compañero costarricense Del Castillo.

En el asunto del gobierno de las provincias, Larrazábal fue especialmente insistente en la defensa de las Diputaciones provinciales, partiendo de la idea de que la exitosa experiencia de las Sociedades Económicas demostraba la importancia de su futura institucionalización. Como muchos otros diputados americanos, el guatemalteco cifraba esperanzas en estas nuevas instituciones y pretendia dotarlas de un poder político real y no meramente consultivo, como contrapeso a las atribuciones de los jefes políticos. Idea que los representantes peninsulares neutralizaron, acusándola de federalismo encubierto.

Por su parte, Del Castillo participó en las comisiones de Honor, Asuntos Ultramarinos, Justicia, Sanidad y Hacienda. Su participación en la discusión de los artículos de la Constitución empezó por el reclamo de ciudadanía para los afrodescendientes libres, concretamente en favor de los garífunas de Trujillo, Honduras, ante la propuesta de hacerlos abandonar el lugar, incluida la posibilidad de ser trasladados a una isla desértica. Paralelamente, al llamar a incentivar la educación de los pueblos indígenas, propuso que en el artículo $2^{\circ}$ sobre los requisitos para ser ciudadano y disfrutar de derechos que establecía que era para ello indispensable saber leer y escribir, pidió que se ampliara el periodo de tiempo para los indigenas, mientras se buscaban promover eficazmente los medios para instruirlos. Valorando la importancia para que cada provincia tuviese un diputado en las Cortes, cuando se discutió el artículo que estipulaba el número de habitantes necesarios para elegirlo, Del Castillo defendió un número menor para aquellas provincias que no tuvieran la población suficiente, como era el caso de la Costa Rica, de manera que éstas contaran con opciones para ser representadas en las Cortes. A su vez, cuando se discutió cuántos deberían ser los miembros del Consejo de Estado, luchó para que el número de los procedentes de América fuera igual al de los Peninsulares. Sabiendo el problema que se tenía con los cargos perpetuos en el Consejo de Estado, opinó para que a tales puestos se les señalara una cantidad determinada de años a fin de evitarla acumulación temporal. De esa forma se contrapuso a lo afirmado por Larrazábal, quien pidió que subsistieran por lo menos la mitad de estos, defendiendo los intereses de la élite de la Nueva Guatemala.

En la misma línea de hacer más eficaz la estructura de gobierno en América, al discutirse el artículo constitucional que determinaba cuántos secretariados debía tener el Poder Ejecutivo y, dentro del mismo, cuántos debían crearse para América, Del Castillo defendió la creación de un despacho para la América septentrional y otro para la meridional. Otra opción que apoyó fue la de crear tres ministerios distintos: Gobernación, Gracia y Justicia, y Hacienda. En la misma línea, peleó en el campo de los ayuntamientos, empezando para que no fueran presididos por el jefe político, lo que atrofiaba la tarea de este organismo tan importante para los pueblos, en la medida en que, si éste no estaba presente, no se podía sesionar, Para paliar la asistencia del jefe político, pidió que en su ausencia el Ayuntamiento fuese presidido por el alcalde. 
Del Castillo defendió con ardor la separación de poderes, no solo a nivel del gobierno general sino a nivel local. Asimismo, se unió a los diputados de centroamericanos para reclamar que se separara el gobierno político del militar, los que estaban reunidos en el Jefe Político. Sabiendo del importante papel que se le dio a las Diputaciones provinciales para el desarrollo de los pueblos a nivel económico, defendió en solitario que a cada provincia del Reino de Guatemala le dieran una diputación. Al final, logró que por lo menos se le otorgaran dos a todo del Reino (Guatemala y Nicaragua). Por último, consideró que, por respeto a la Constitución, debía de vigilarse judicialmente las infracciones a ésta.

\section{LA LABOR PARLAMENTARIA DE LOS HERMANOS DEL LLANO 12}

De los hermanos Del Llano, quienes actuaban como diputados suplentes, queda claro que, dedicado plenamente a sus actividades comerciales en Cádiz, Andrés de Llano no tuvo una participación destacada en Cortes, donde sus ausencias resultaron notorias. Participó en las Comisiones de Examen de Listas de Empleados, de Comercio, de Marina y en la de Inspección del Diario de las Cortes. Al igual que los diputados Larrazábal y Del Castillo, tomó parte en la discusión sobre igualdad de representación y, cuando por sorteo debió abandonar la Asamblea, mandó expedir una certificación honorífica a su favor y su nombre resultó mencionado para un puesto en el Consejo de Estado.

Por su lado, el papel de su hermano Manuel fue más importante. Desde la primera sesión se alineó con los liberales y se posicionó junto en el bloque de los diputados americanos. Fue elegido para varias Comisiones, entre ellas la de la redacción del Decreto de publicación en América de instalación de las Cortes, así como en la del Colegio de Cirugía Médica, la de libertad individual, la de Premios y Honores y la del Diario de Cortes, en la que sustituyó a su hermano Andrés. Luego, en el mes de abril de 1812 resultó electo secretario de las Cortes.

En la Asamblea constituyente, Del Llano se pronunció en favor de la libertad de imprenta y sobre la igualdad de representación entre peninsulares y americanos. Sin embargo, fue en la Comisión de Guerra donde prestó mejor sus servicios debido a su condición de militar de profesión, pues había realizado sus estudios en el Colegio Militar de Segovia, de donde era graduado como ingeniero militar. En todas sus intervenciones sobre el tema se orientó hacia una liberalización y democratización del ejército a partir de una disciplina sin despotismo.

Pero su más importante propuesta se refirió a la libertad individual. Manuel del Llano propuso el 14 de diciembre de 1810 que se nombrase una Comisión que se ocupara de redactar "una ley al tenor de la del habeas Corpus que rige en Inglaterra, que asegure la libertad de los ciudadanos". Seguido el trámite parlamentario, su proposición fue integrada al Título V de la Constitución, que se refiere al Poder Judicial.

12 Arturo Taracena Arriola, "Manuel Del Llano", "Andrés del Llano" en Diccionario Biográfico de Parlamentarios Españoles, 1820-1854), Madrid, Cortes Generales, 2012-2013. (CD) 


\section{LA REACCIÓN ABSOLUTISTA DEL CAPITÁN GENERAL BUSTAMANTE Y GUERRA 13}

La Constitución de Cádiz, promulgada el 19 de marzo de 1812, tenía como principales novedades la delimitación de las atribuciones del Monarca, el papel del Consejo de Estado, la definición del sistema electoral, las facultades de las Cortes, más las reformas que la Representación Nacional aprobó. Desde un año antes, el capitán general José Bustamante y Guerra se dedicó a entorpecer no sólo la elección de los diputados por el Reino de Guatemala, sino además su labor cuando estuvieron en España. Los documentos de crítica de Bustamante y Guerra fueron conocidos en Cádiz antes de que la Constitución fuese promulgada. En sus informes al Rey, no dejó de hacer hincapié el influjo que en el proyecto constitucional guatemalteco elaborado por el Ayuntamiento había tenido de la Constitución francesa de 1794. El Proyecto guatemalteco ya había sido conocido por la Comisión de Constitución antes de que ésta terminase su trabajo, y en ella se dio su deliberación en tres momentos entre el 18 de agosto y el 20 de diciembre de 1811. Larrazábal tomó posesión el 25 de agosto de ese año, cuando ya se había presentado la primera deliberación.

Con anterioridad, entre los meses de julio a octubre de 1810 , los principales cabildos del Reino de Guatemala notificaron oficialmente haber recibido noticias de la instalación del Soberano Consejo de Regencia y del nombramiento de diputados a Cortes. En el seno del cabildo capitalino, la noticia causó acalorados debates, pues algunos de sus miembros defendieron la idea de que la transferencia de poder de la Junta a la Regencia no era válida en la medida de que los "pueblos", entendidos como los detentores de la soberania, ${ }^{14}$ eran los únicos que podían otorgársela a los miembros del Consejo Real. Al final, todos los cabildos del Reino se pusieron de acuerdo para reconocerlo a partir de la idea de que la soberanía de la Monarquía se basaba en la interacción de dos elementos: la comunidad y el soberano. Es decir, la sobrevivencia del principio basado en el principio pactista. Sin embargo, desde 1811, los primeros decretos constitucionales habrian de producir tensiones entre, por una parte, los cabildos criollos e indígenas -reconocidos por el nuevo sistema político como ayuntamientos constitucionales- y, por la otra, las autoridades españolas en el Reino.

Dichas tensiones se dieron en torno a al juramento de la Constitución gaditana, que reconocía la figura constitucional de la Monarquía, el llamado a la renovación de diputados a Cortes, el retraso de la tan anhelada autorización de libertad de imprenta, la retención de la llegada de los decretos y correspondencia

13 Véase: Mario Rodríguez, El Experimento de Cádiz en Centroamérica, 1808-1826, México, Fondo de Cultura Económica, 1984, Timothy Hawkins, José de Bustamante and Central American independence:colonial administration in an age of imperial crisis, Tuscaloosa, University of Alabama Press, 2004 y Jordana Dym” Soberanía transitiva y adhesión condicional: lealtad e insurrección en el reino de Guatemala, 1808-1811" en Revista Iberoamericana de Filosofía y Humanidades, $\mathrm{N}^{\circ}$ 18, Segundo semestre, Universidad de Sevilla, 2007, pp. 196-219; Xiomara Avendaño Rojas. Centroamérica entre lo antiguo y lo moderno. Institucionalidad, ciudadanía y representación politica, 1810-1838. Castelló, Universitat Jaume I, 2009.

14 Jordana Dym, "Our Pueblos, Fractions with No Central Unity": Municipal Sovereignty in Central America, 1808-1821" en Hispanic American Historical Review 86 (3), Duke University Press, 2006, pp. 431-466. 
gaditana y la parsimonia con que el capitán general Bustamante y Guerra tenía para responder a los oficios de los cabildos. Ello habría de abrir una serie de protestas constitucionalistas en contra de las autoridades españolas, empezando por la de los cabildos de San Salvador y Granada, Nicaragua, ese año de 1811 y, más tarde, por la "Conspiración de Belén", llevada a cabo en la Nueva Guatemala en 1813.

Durante el año de 1812, Bustamante y Guerra pasó a obstaculizar el proceso electoral de los cabildos, notificando su convocatoria solamente hasta los primeros dias del año siguiente. Asimismo, obstruyó el proceso de elecciones para la renovación de diputados en las Cortes, mientras evitaba responder oficialmente a las diversas peticiones que le enviaban los cabildos desde las provincias del Reino. Por ello, con la llegada el 23 de junio de 1814 de las instrucciones restauradoras, que suprimian las Cortes de Cádiz e ilegalizaban la Constitución de 1812, como capitán general, tales medidas le permitieron a Bustamante y Guerra exigir a los ayuntamientos y diputaciones responder a su única autoridad. En pocas palabras, con ellas se anulaba el ejercicio soberano de las entidades políticas en el Reino de Guatemala.

\section{DESTINO FINAL DEL DIPUTADO LARRAZÁBAL Y DE LOS DOCUMENTOS GUATEMALTECOS 15}

La restauración el 4 de mayo de 1814 de Fernando VIl significó la vuelta al absolutismo, la disolución de las Cortes y el desconocimiento de la reforma intentada. Bustamante y Guerra aún no había entregado el cargo a su sustituto a raíz de las acciones emprendidas contra él por el guatemalteco José de Aycinena como miembro del Consejo de Estado y por los alegatos de los ediles centroamericanos. Por ello, aquél pudo echar a andar los mecanismos del orden absolutista a la vez que empujó una serie de persecuciones contra funcionarios y hombres prominentes del Reino, que terminaron por su encarcelamiento en los fuertes de Omoa, La Habana y Cádiz. El reinado de Fernando VII fue muy enfático en perseguir a los aquellos diputados defensores de la Constitución de 1812. En Madrid se ordenó el arresto de los considerados como más importantes y peligrosos, entre los que se incluyó a Antonio Larrazábal, único centroamericano. Por Real Orden de 17 de diciembre de 1815, se le condenó a seis años de reclusión en el convento que señalara el arzobispo de Guatemala, para que bajo su dirección se dedicara a "aprender religión y fidelidad a su rey". Ello le implicó estar preso tres años en Cádiz; luego en el convento de la Orden de Belén de La Habana, para entrar a la ciudad de Guatemala, en calidad de preso, el 16 de abril de 1819, con destino al convento de Belén, de donde salió en el año 1820, como resultado de la nueva revolución liberal española encabezada por el general Rafael Riego de Cabezas de san Juan en enero de ese año.

Por su parte, el regidor Antonio Juarros, a pesar de haber sido secretario y director de la Sociedad Económica de Amigos del País, Primer Cónsul del Real Consulado de Comercio y alcalde de la ciudad de Guatemala en 1808, a raíz de sus fuertes enfrentamientos con Bustamante y Guerra, a los pocos dias de su fallecimiento el 26 de diciembre de 1814, por decreto de Fernando VII de 31 de enero de 1815, se ordenó que se le privase a perpetuidad del derecho a ocupar

15 Ídem. 
cualquier tipo de cargos. No mejor suerte corrió tanto la Declaración de derechos y el Proyecto constitucional, pues el capitán general Bustamante y Guerra ordenó que fuesen quemados en la ciudad de Guatemala, el día 22 de diciembre de 1816.

\section{LA REBELIÓN DE RIEGO Y EL INICIO DE LA COYUNTURA INDEPENDENTISTA.}

Los intensos cambios políticos y económicos que produjo la coyuntura abierta en 1808 dejaron su huella en el Reino de Guatemala y, cuando en 1820, a raíz del levantamiento de Riego se produjo la restauración de la Constitución liberal, en la Audiencia de Guatemala habría de producirse el levantamiento indígena más importante en su territorio. En San Miguel Totonicapán y otros pueblos k'ichés de este partido, luego de hacer huir al alcalde mayor, los rebeldes decretaron que impartirian justicia, cobrarian impuestos, castigarian a los intermediarios indígenas, a la vez que se dotaron de un líder, Atanasio Tzul (1760-¿), a quien parece se le coronó como rey, entrando de esa forma en la memoria colectiva maya. Este fue un levantamiento que no cuestionaba la autoridad del rey español, sino que estaba dirigido hacia quienes ejercian directamente el poder colonial, el cual, a pesar de los postulados liberales gaditanos, seguía manteniendo en territorio guatemalteco la explotación y subalternidad de las comunidades indigenas.

Fue un levantamiento que tuvo repercusiones inmediatas en el entorno regional de los Altos guatemaltecos, ya dominado por la hegemonía de un centro administrativo colonial como Quetzaltenango. Una ciudad altense dirigida por una élite comercial y terrateniente criollo-ladina, con una importante estructura de milicias, dirigida a su vez por el coronel español Prudencio de Cozar, quien nuevamente fue el encargado de planificar la respuesta militar directa en contra de los rebeldes y salir de ella victorioso. Sin embargo, para entonces su victoria ya no defendía los intereses de la Corona, sino de la élite criolla que estaba a punto de declarar la independencia de España. Por matrimonio estaba casado con una prominente altense. Una nueva etapa se abriria para los indigenas en su secular resistencia en contra de la subalternidad y todas sus consecuencias económicas, sociales y politicas. Entre sus acciones destacaría el manejo de las leyes por parte de sus autoridades.

\section{LA ELECCIÓN DE DIPUTADOS A CORTES EN $1820^{16}$}

Mario Rodríguez señala las diversas irregularidades que en esa coyuntura se dieron para elegir diputados a Cortes por el reino de Guatemala. El 12 de marzo de 1821, Mariano Córdova González (¿-1835), quien desde 1815 fungia como maestro de la Escuela de Letras San José de Calazans, bajo el patronato del Ayuntamiento de la Nueva Guatemala, fue electo a las Cortes Españolas por los corregimientos de Quetzaltenango y Totonicapán. El 25 abril, la Diputación Provincial acordó que Hacienda Pública cubriese los viáticos de los diputados

16 Luis Pedro Taracena Arriola, "Mateo Ybarra”, “José Mariano Méndez Cordero" en Diccionario Biográfico de Parlamentarios Españoles, 1820-1854), Madrid, Cortes Generales, 2012-2013. (CD) y Arturo Taracena Arriola, "Mariano Córdova", "José María Álvarez", Andrés del Llano" en Diccionario Biográfico de Parlamentarios Españoles, 1820-1854), Madrid, Cortes Generales, 20122013. (CD) 
ante las Cortes de Madrid por la provincia de Guatemala. E1 4 de mayo, Córdova volvió a solicitar la asignación de fondos para el viaje, el cual nunca llegó a realizar luego del fallecimiento por cólera en Honduras del otro diputado guatemalteco, doctor José María Âlvarez Estrada. Asimismo, fue electo el 12 de marzo de 1820 diputado por Sacatepéquez y la Nueva Guatemala, el comerciante Mateo Ybarra, siendo su suplente Francisco Argüello, oficial de la Secretaría de Gobierno. En la Península se encontraba Manuel Guerra Marchán, nacido en Guatemala y quien, para entonces, fungía como deán de Tortosa, Tarragona, propuesto como diputado suplente por Sacatepéquez, cargo que nunca asumió, resultando electo por esta entidad en las segundas cortes de 1821, Julián Urruela, quien igualmente residía allí. Lo mismo, los delegados suplentes, José Sacasa y a Juan Nepomuceno de San Juan, quienes promovieron privilegios de importación en Ultramar, contribución directa, crédito público, derecho de asilo y asuntos de milicia y ejército.

En estas Cortes, los dos diputados que sobresalieron por su actividad fueron el mencionado Ybarra y José Mariano Méndez Cordero, quien fue electo diputado por San Salvador y estaba radicado en Madrid. El 29 de marzo de 1820, Ybarra solicitó instrucciones a la Diputación provincial, la cual se las otorgó, con lo que éste puedo embarcarse el 1 de mayo rumbo a España. Al arribar a Cádiz, presentó sus poderes, lo cuales fueron aprobados. Participó en la comisión del Ultramar y en las discusiones sobre la Memoria presentada por el ministro de esta dependencia. A raiz de la Independencia del Reino de Guatemala, el 15 de septiembre de 1821, Ibarra solicitó licencia para retirarse de las cortes, la cual se le otorgó. El 23 de diciembre, junto a otros diputados guatemaltecos, desde Madrid envió una felicitación al pueblo de Guatemala por su independencia. Estando aún en Madrid, el 15 de junio de 1822, éste publicó el Voto Ybarra, en el que planteaba formas para establecer la paces y diseñar las futuras relaciones diplomáticas con España. Ibarra trajo consigo a Guatemala el Código Penal español de 1822, en el que posteriormente se basaría el emitido en San Salvador en 1826.

Méndez Cordero, de quien se objetó su elección y fue defendido por dos diputados americanos, el mexicano Pablo de la Llave y el peruano Juan Freire, tuvo una labor intensa en Cortes. Presentó la Memoria del estado politico y eclesiástico de la capitanía General de Guatemala, fechada el 17 de mayo de 1821 y publicada ese mismo año en Madrid por la Imprenta Fermín Villalpando. En ésta señalaba que la dominación española en América tenía un balance negativo, pues en tres siglos no había habido grandes progresos para el Reino de Guatemala, sino destrucción de pueblos, inexistencia de instrucción y de civilización, y miseria. También puntualizaba que los intereses de Guatemala estaban "encontrados y contrariados" con los de los pueblos de las Provincias "por razón del comercio interior y sus largas distancias", por lo que sugeria una reorganización administrativa, creando ocho provincias en lugar de cinco. A su vez, denunciaba que, en el Reino de Guatemala, los esclavos eran pocos debido a la oposición de la Audiencia. Paralelamente, presentó el proyecto de ley de Señoríos, propuso quemar las causas del tribunal de la Inquisición y un nuevo plan para la Hacienda de Ultramar. Solicitó abolir el Montepío del Añil, que afectaba a los productores salvadoreños, y destinar sus fondos a escuelas de primeras letras. Pidió quitar el estanco del tabaco y liberar el diezmo a los frutos guatemaltecos, medida similar a la que se había dictado en torno al añil y el 
azúcar. Planteó en convertir en ciudadanos españoles a los mulatos del Reino, a los que consideraba mestizos, a condición de que fueran hijos legítimos y no haber llegado a Guatemala como esclavos africanos. Presentó un plan sobre la formación de milicias y otro sobre la abolición de las mitas, repartimientos y mandamientos, retomando las ideas de Larrazábal y Del Castillo. A su vez, puso a consideración de las Cortes repartir tierras en propiedad a los indígenas y otorgar tierras baldias en las costas norte y sur del Reino a fin de garantizar la soberania guatemalteca de las mismas. Participó en el dictamen sobre la exención del pago de diezmos a los plantadores de café en la Nueva España. En la Comisión sobre Juicios de Conciliación de Instrucción Pública y en la de Ultramar. En España obtuvo fondos para construir el sagrario de la catedral de Guatemala y alentó la idea de crear la Universidad de león, Nicaragua, con el carácter de tercera enseñanza y otras más de segunda enseñanza en San Salvador, Comayagua (Honduras) y Cartago (Costa Rica). Por último, en materia de enseñanza, propuso la creación de una Dirección general de Estudios y una cátedra de comercio en la Pontificia Universidad de San Carlos de Borromeo en la Nueva Guatemala.

\section{LA DIPUTACIÓN PROVINCIAL DE GUATEMALA Y LA JUNTA PROVINCIAL CONSULTIVA DEL REINO 17}

En mayo de 1821, las Cortes aprobaron la solicitud del Reino de Guatemala de organizar diputaciones provinciales donde previamente existian intendencias. A partir de 1813 habían sido establecidas la de Guatemala, que abarcaba a Chiapas, Honduras, y San Salvador, y la de Nicaragua más Costa Rica. A raíz del decreto de mayo de 1821, Chiapas, Honduras y San Salvador implantaron las suyas, mientras que Costa Rica eligió más tarde una Junta de Gobierno. E1 25 de octubre, Nicaragua instaló su diputación y Costa Rica se mantuvo unida a ésta hasta la declaración de Independencia del Reino un año más tarde. De esa forma, su estructura administrativa quedó desarticulada, dejando en manos de sus élites capitalinas y del voto de sus pueblos las decisiones propias. Por medio de sus cabildos, estos solicitaban a las Cortes audiencias, obispados, puertos, universidades, seminarios propios. De ahí que el Reino pasase a estar dividido en seis provincias, que a futuro afrontarian el destino político del istmo centroamericano.

De esa forma, a raíz de la reinstalación de las Cortes en Madrid en marzo de 1820, los miembros de la Diputación de Guatemala para 1814 pasaron a ocupar el 2 de septiembre sus lugares en ella, mientras que los de Nicaragua fueron reinstalados el 25 de octubre sin autorización de las Cortes. Ésta sólo llegó el 21 de noviembre. Asimismo, los centroamericanos decidieron elegir otra diputación

17 Xiomara Avendaño, Centroamérica entre lo antiguo y lo moderno. Institucionalidad, ciudadanía y representación politica, 1810-1936. Castelló, Universitat Jaume I, 2009 y "El Gobierno provincial en el reino de Guatemala, 1821-1823" en Históricas digital, México, UNAM/Instituto de Investigaciones Históricas, 29 de junio de 2018, pp. 321-354; Aaron Pollack, “Totonicapán, 1820: ¿una de las puntas del iceberg?” en Aaron Pollack (coordinador), La época de las independencias en Centroamérica y Chiapas. Procesos politicos y sociales. México, Instituto Mora-UAM Iztapalapa, 2013, pp. 189-224; Mario Vázquez Olivera, "Centroamérica en la senda de Cádiz, 1820-1823", en Manuel Chust (ed.) ¡Mueran las cadenas! El trienio liberal en América (1820-1824), Granada, Editorial Comares, pp. 77-113. 
en Comayagua, Honduras, a provechando que esa provincia debía de enviar un delegado a la Diputación provincial. Paralelamente, el Ayuntamiento de la Nueva Guatemala pasó a ejercer el papel de consejero del capitán Gabino Gaínza (17521823). Finalmente, como organismo rector, se creó la Junta Provincial Consultiva, la cual fue instalada el 17 de septiembre de 1821 con el propósito que ejerciese un interinato mientras se definia la nueva forma de gobierno para el Reino.

La Junta Provincial tomó como primera medida dotarse de un reglamento, que estableció la creación de varias comisiones: Diputaciones, y Elecciones, Seguridad y Defensa Pública, Hacienda, Comercio, Industria, Agricultura Estadística, Instrucción y Asuntos Indigenas, dirigidas por sus miembros con el apoyo de las corporaciones existentes. Cargos que fueron ratificados por las provincias mediante poderes a sus respectivos representantes.

Como lo ha señalado Avendaño, la Junta aprobó las diputaciones en cada provincia y ejerció de directora de los asuntos de los ayuntamientos, entidades que estaban encargadas de dar a conocer las medidas emanadas de ésta. Ello implicó velar por el desarrollo de las elecciones y organizar las milicias que garantizasen el orden. Asimismo, en torno a la justicia, el papel de jueces de letras recayó en los jefes politicos, quienes estarian encargados resolver todas las causas. Medida contestada por las comunidades, las cuales exigieron que estos fuesen designados por elección y que los alcaldes tuviesen la potestad de resolver asuntos criminales. En cuanto al tan contestado tributo por parte de los indigenas, la Junta decidió que no se eliminaría tal asunto, pero aceptó demandas de rebaja o de eliminación en casos extremos de pobreza o abuso. Decisión que fue apoyada por el clero y los alcaldes mayores, que eran los que más se beneficiaban de tal recaudación. Tal mantenimiento del estatus quo conllevó el importante levantamiento indígena k’iché en el partido de Totonicapán durante julio y agosto de 1820, lo que provocó el miedo entre las autoridades guatemaltecas, las que se encargaron de mediar las tensiones por medio de la Diputación y la Junta Provinciales.

\section{LAS DIFICULTADES DE APLICACIÓN DEL ESPÍRITU GADITANO 18}

Como indicaba la Diputación provincial bajo la presidencia del Jefe Político Gabino Gaínza, su fin era "llenar los fines de la Constitución" de Cádiz. Tal ejercicio trajo varios niveles de tensión entre las instancias inferiores. El Ayuntamiento de la ciudad de Guatemala entró en competencia con la Audiencia, y los alcaldes mayores y corregidores quisieron seguir imponiendo su ley frente a los cabildos de los pueblos. Asimismo, la Iglesia buscó mantener su influencia en la organización del proceso constitucional.

Una de las primeras medidas fue, por razones electorales, la de mandar a hacer los padrones de los pueblos. De inmediato resultaron problemas en torno a la definición del peso poblacional de los Partidos, la delimitación de las provincias

18 Recopilación de documentos históricos desde la fundación de la Nueva Guatemala en 1776 hasta el año de 1865. Opúsculo Número 4, Guatemala, Diario de Centro América, 1930; y Xiomara Avendaño, "El Gobierno provincial en el reino de Guatemala, 1821-1823" en Históricas digital, México, UNAM/Instituto de Investigaciones Históricas, 29 de junio de 2018, pp. 321-354; Arturo Taracena Arriola y at. lat. Etnicidad, Estado y nación en Guatemala, 1808-1944. Vol. 1. Guatemala, CIRMA, 2002. 
electorales y los procedimientos de las juntas electorales. Detrás de todo, ésta consideraba que estaba la "falta de inteligencia" para aplicar el sistema constitucional. Para ello, se propuso dirimir los reclamos en la Audiencia territorial, de acuerdo con el contenido del Decreto del 12 de marzo de 1813. De esa manera, poco a poco, continuar con la a extinción de los gobernadores y cabildos antiguos en favor de la figura del alcalde constitucional, creada con base en los artículos $311^{\circ}$ y $312^{\circ}$ de la Constitución gaditana En esa dirección, el Ayuntamiento constitucional de la ciudad de Guatemala fue designado para velar por la planificación de todo el sistema constitucional. Por tanto, con previa propuesta de la Audiencia Provincial, los subdelegados, alcaldes mayores y corregidores debian de ser nombrados por el Jefe Politico a partir de ternas para evitar nombramientos a dedo, tan comunes hasta ese momento. Las protestas de los asuntos que le correspondian a éste debían de hacerse vía la secretaría de la Diputación, especialmente los recibidos por parte de los Ayuntamientos constitucionales. De esa forma, mientras los alcaldes mayores pasaron a nombrar a los jueces de primera instancia, en los alcaldes primeros de los ayuntamientos constitucionales recayeron las funciones administrativas de orden económico y político, de acuerdo con el Acta del 12 de abril de 1821.

En materia de tributación, el 27 de marzo de 1821 el gobierno guatemalteco publicó un auto para que se evitase hacer "novedades en el sistema de Hacienda", pues la Audiencia no tenía derecho a proponer para las provisiones en virtud del artículo 15 del Decreto del 13 de septiembre de 1813. Por tanto, hasta nueva resolución de las Cortes, los pueblos debían de continuar el pago del tributo con el tenor de dicho decreto real, lo que impedia a los Ayuntamientos disponer de esas cantidades. Asimismo, los pagos de escritos y papel debían de ser saldados por la comunidad en pueblos de indios, y los de los propios y arbitrios en aquellos que no lo fuesen y, a partes iguales, en los que los indígenas y los no indígenas se hallasen mezclados.

La Constitución gaditana había regulado en su artículo $311^{\circ}$, que las leyes determinasen el número de individuos de cada "clase" en el que debían de componerse los ayuntamientos de los pueblos con respecto a su vecindario. Asimismo, en su artículo $320^{\circ}$ creo la figura de secretario, individuo que supiese el castellano, leer y escribir, lo que abrió la puerta a las castas al poder local. Ello provocó disensiones en la Diputación por considerarlos algunos de sus integrantes como injustos y como una actitud autoritaria de parte de los Corregidores y alcaldes. A raíz de la restauración, asumiendo el decreto de 28 de diciembre de 1814, se restablecería la figura de Justicia de indios, que nuevamente ejerció la ley de acuerdo con la Leyes de Indias y, más tarde, el 20 de diciembre de 1816, se hizo lo mismo con la de Intérprete de indios, renunciando a la implantación gaditana de un único sistema de administración de justicia.

Por Decreto de Cortes, en 1813 habian sido suprimidos los tributos a cambio de una contribución principal siguiendo la lógica del acceso a la ciudadanía de los habitantes en cada territorio. Empero, los primeros se seguian cobrando en el Reino de Guatemala, motivando los reclamos de los Pueblos, especialmente de los indígenas. El subterfugio esgrimido por las autoridades centrales era que, elevado el asunto "por las Cortes a la Comisión ordinaria de Hacienda, en unión con la de Ultramar, y convencido que el mismo Gobierno Supremo se creyó sin facultades para resolver en materia de contribuciones, sujeta por la Constitución al juicio de las Cortes, y que mientras éstas no resuelvan, no puede hacerse novedad". Todo 
ello a pesar de que el Decreto de abolición de los tributos no estaba derogado, contrariando los conceptos de "ciudadano" y "tributario" fijados en la Cortes.

Por otra parte, según orden de la Audiencia territorial guatemalteca, el sustento de los alcaldes mayores y los subdelegados debía de ser completado por el aporte de los pueblos. A su vez, el artículo $25^{\circ}$ de la Ley de 9 de octubre de 1812 establecía que los Jueces de Letras serian pagados con los fondos de propios y arbitrios de los Ayuntamientos, mientras que Hacienda debía cubrir los empleos públicos y militares.

En cuanto a la discusión en la Diputación sobre el proceder de los Ayuntamientos y la formación de Milicias Nacionales. El reglamento emitido que estableció el Decreto de las Cortes de 14 de octubre de 1812 señalaba que en este ramo había una diferencia entre las Provincias de América y las de la Península, pues en las primeras solamente pasarian a conformarlas los ciudadanos de 18 a 50 años que servian en los Cuerpos Urbanos, por lo que no podian levantarse indistintamente milicias en los pueblos del Reino. Medida que dejaba al margen a los indigenas para que funcionasen como miembros de tareas auxiliares y en previsión de no armarlos por miedo a revueltas.

\section{EL DEBATE EN LA PRENSA 19}

Con la restauración en 1820 de la Constitución gaditana se organizaron tertulias patrióticas, espacios de sociabilidad política, donde se pasó a debatir nuevamente la posibilidad de que el Reino de Guatemala tuviese un gobierno constitucional monárquico, dando también espacio a los partidarios que reclamaban que éste tuviese la forma republicana. Los funcionarios reales participaron activamente en el debate público sobre la reinstalación de la Constitución. Además de las tertulias patrióticas, es innegable que la postura asumida por ellos como defensores del Monarca y la Constitución, los llevó a resaltar el papel de la "fidelidad" como elemento central de los nuevos ciudadanos. Por otro lado, los funcionarios rescataron que la instauración de la ciudadanía permitía que los intereses de los antiguos estamentos se mezclaran y que la representación ejercida por notables en las Cortés fuese ejercida gracias a intereses mutuos. Este es el caso de Francisco de Paula Vilches, Regente de la Audiencia, en su discurso del 24 de julio de 1820, cuando afirma que

Si la Constitución política de la Monarquía Española sancionada por las Cortés Generales y extraordinarias de 1812 pudo ser por desgracia hasta ahora objeto de alteraciones, y motivo de disensiones doméstica en nuestra Nación, desde que la aceptó, juró y promulgó el Rey por sus memorables decretos de marzo, ya no debe ser para los españoles de ambos mundos, sino un vínculo de paz y de concordia. [La Constitución] solo debe ser un código venerable, una ley digna de respeto, que no admite sino la obediencia y cumplimiento de los súbditos. ${ }^{20}$

19 Escritos del Doctor Pedro Molina, El Editor Constitucional. III Tomos, Guatemala, Ministerio de Educación Pública, 1954; Escritos del licenciado José Cecilio del Valle. El Amigo de la Patria, II Tomos, Guatemala, Editorial José Pineda Ibarra, 1969.

20 Discurso pronunciado por el señor D. Francisco de Paula Vilches Regente de esta Real Audiencia Territorial, el día 24 de julio, en el acto de instalación del Tribunal en el sistema de la Constitución y la ley de 9 de octubre. Guatemala: Oficina de Ignacio Beteta. p. 4. 
Esta opinión fue emitida justo en el momento en que el debate público, que ocurría gracias a la libertad de imprenta, apenas iniciaba.

En la ciudad de Guatemala se fundaron los periódicos El Editor Constitucional (28 de julio de 1820) y El Amigo de la Patria (16 de octubre de 1820), dirigidos respectivamente por Pedro Molina y José Cecilio del Valle. En sus páginas la pedagogía política utilizada para defender las posiciones monárquicas y republicanas abarcó desde la reproducción de textos filosóficos hasta los poemas y epígrafes patrióticos con los que se defendia con variantes las bondades del régimen representativo.

En esa dinámica, surgieron los primeros bandos politicos. El favorable a las nuevas autoridades políticas encabezadas por el capitán general Gainza, y liderada por Del Valle y la familia Aycinena, la más poderosa del Reino, cuyos miembros eran denominados como 'bacos' o 'gases' por su defensa de una monarquía constitucional y estar vinculados al Consulado de Comercio. Estos estaban apoyados por la oligarquía colonial concentrada en la capital del Reino, con partidarios en otras ciudades del istmo como Granada, Comayagua y Cartago. En lado opuesto estaba el bando minoritario de los 'cacos', liderado por Molina y el abogado Francisco Barrundia, convencidos republicanos, sostenidos por individuos de profesiones liberales y maestros artesanos en ciudades como la propia Guatemala, San Salvador, Tegucigalpa, León y San José.

En el Editor Constitucional, Pedro Molina comenzó defendiendo la idea la ciudadanía como expresión de la soberanía del pueblo, elemento inherente al pacto social entre los habitantes del Reino, tal y como lo pregonaba la Constitución gaditana. Y ello implicaba a su vez defender la igualdad entre americanos y españoles. Igualdad civil, que debía de incluir a los afroamericanos y a los indigenas, dándoles a sus miembros la ciudadanía española. Un primer paso sería abolir las Protectorias de Indígenas. Idea que respaldó Del Valle en $E l$ Amigo de la Patria al subrayar que hasta entonces el régimen restaurador no habia permitido "vivir unidos por los vínculos de la sociedad a los indios, ladinos y españoles". Asimismo, estaba convencido que para ello había que abolir los privilegios corporativos, promoviendo la interrelación de las clases en los espaciosa de trabajo y de la educación.

Usando la modalidad de diálogos, El Editor defendía, a su vez, la libertad de comercio, siguiendo la línea argumentativa de los Apuntamientos, así como la libertad de imprenta. Ponía en duda la utilidad de la Constitución gaditana para los americanos, basándose en la idea de que, en el Derecho de Gentes, "cada nación es como un individuo, libre e independiente". Con osadía, este periódico terminaba por llamar a proclamar la independencia, lo que le trajo varias veces la intervención del Fiscal, elevando sus quejas a la Junta Provincial.

Por su parte, El Amigo de la Patria centraba sus ataques contra el monopolio de la aristocracia capitalina guatemalteca, señalando que ésta acumulaba 64 de los puestos administrativos más importantes del Reino con un sueldo total de 89.025 pesos anuales. Del Valle manejaba las estadísticas y los datos económicos para sustentar los derechos de los centroamericanos.

Las diferencias entre cacos y gases, ante a la posibilidad de lograr la Independencia de España y después de su proclamación, girarian en torno a la velocidad y profundidad del corte con el legado colonial, las relaciones con la Iglesia, la secularización del Estado y de la educación, la abolición de las 
corporaciones, la necesidad de un gobierno centralista o uno federal, la profundidad de la autonomía de las provincias en materia de fiscal, etc. Es decir, los elementos que a finales de la década de 1830 definirian a liberales y conservadores. $^{21}$

\section{LA INDEPENDENCIA DE ESPAÑA 22}

Al conocerse en la provincia de Chiapas el Plan de Iguala proclamado por Agustín de Iturbide, sus autoridades y diputación declararon su independencia de España y de Guatemala, y su unión a México. En la ciudad de Nueva Guatemala, las autoridades encabezadas por el capitán general Gaínza, con el apoyo del clero y del Real Consulado redactaron el Acta de Independencia el 15 de septiembre de ese año de 1821, que como idea central planteaba la constitución de un congreso para febrero de 1822, el cual estaría integrado por los diputados electos por las juntas electorales de provincia origen gaditano para determinar la forma de gobierno y elaborar la ley fundamental del nuevo Estado. Mientras tanto, la Constitución de 1812 regiría el gobierno del antiguo Reino. Sin embargo, se dejaba abierta la fórmula de que eran los "pueblos" los que tenían, por medio de sus ayuntamientos constitucionales, la potestad de elegir.

Sin embargo, en su primer artículo, el Acta dejaba en claro quiénes o qué grupos de poder impulsaban la gesta emancipadora y los límites que la noción de ciudadanía habria de tener a partir del ejemplo emancipador mexicano:

Primero. Que siendo la Independencia del Gobierno Español la voluntad general del pueblo de Guatemala, y sin perjuicio de lo que determine sobre ella el Congreso que debe formarse, el señor Jefe Político la mande publicar para prevenir las consecuencias, que serian terribles, en el caso de que la proclamase de hecho el mismo pueblo". ${ }^{23}$

Paralelamente, el Acta de Independencia muestra la influencia politica de la Constitución de Cádiz, tomando en cuenta que ésta había sido reimplantada en

${ }^{21}$ Adolfo Bonilla afirma que una consecuencia perdurable del debate entre el Editor y el Amigo de la Patria fue la utilización de un lenguaje que calificó como conservadores o serviles a posturas más cercanas al liberalismo. Y que la historiografia del siglo XIX retomó como parte de sus propias peleas. Adolfo Bonilla Bonilla, "The Central American Enlightenment, 1770-1838: An Interpretation of Political Ideas and Political History", Tesis de doctorado, Universidad de Manchester, 1996, pp. 307-327.

22 Mario Vázquez Olivera, "El Plan de Iguala y la independencia guatemalteca" en Históricas digital, México, UNAM/Instituto de Investigaciones Históricas, 29 de junio de 2018, pp. 385-422; Xiomara Avendaño, Los escenarios del poder en 1821: la juramentación del Acta de la Independencia en la provincia de Guatemala" en Aaron Pollack (coordinador), La época de las independencias en Centroamérica y Chiapas. Procesos politicos y sociales. México, Instituto Mora/ UAM Iztapalapa, 2013, pp. 225-250; Arturo Taracena Arriola, "Nación y República en Centroamérica (1821-1865)" en Taracena Arriola, Arturo y Jean Piel (compiladores, San José de costa Rica, Editorial Universitaria de Costa Rica, 1995, pp. 45-61. Colección Istmo.

23 "Acta de Independencia", Memoria Centroamericana, Instituto de Historia de Nicaragua y Centroamérica,

http://memoriacentroamericana.ihnca.edu.ni/uploads/media/Declaracion_de_independencia.pdf consultado 25 de abril de 2021. 
1820. Como señala Benavides, en su artículo $7^{\circ}$, se indicaba que sus autoridades seguirian ejerciendo sus atribuciones de acuerdo con la Constitución, los decretos y las leyes de las Cortes. Asimismo, el artículo $3^{\circ}$ apuntaba que se debía de constituir un Congreso que estableciese el tipo de gobierno con que el hasta entonces Reino a futuro se dotaría. Labor que no se encomendó a los Ayuntamientos, sino a las Juntas electorales de cada provincia y que ya estaban establecidas desde la elección de los últimos diputados centroamericanos a Cortes en España en 1820. Ello explica por qué se reclamó la creación de una Junta Provincial Gubernativa, como fue el caso de Costa Rica. A su vez, tomando el modelo de las Juntas Provinciales creadas por la Constitución de 1812 y el proyecto de Capitanía General presentado ante las mismas. ${ }^{24}$

El Acta de Independencia reconoció la autoridad del excapitán general Gaínza y, para acompañarlo en el ejercicio del poder, decretó la conformación de esa Junta Provisional con carácter consultivo, conformada por los miembros de las diputaciones provinciales hasta ese momento existentes, a los que se sumarian otro tipo de representantes emanados de las provincias. Tal documento fue enviado a los cabildos y a las corporaciones existentes para ser juramentada. Es decir, al Cabildo Eclesiástico, al Consulado de Comercio, al Colegio de Abogados, al Ayuntamiento Constitucional de la Nueva Guatemala, al Claustro de la Pontificia Universidad de San Carlos de Borromeo, a los jefes de la Milicia y a los gremios de artesanos existentes. Se adhirieron a la iniciativa los principales ayuntamientos de las provincias de Guatemala, San Salvador Honduras, Nicaragua y Costa Rica. Por su parte, para la Junta Provincial la principal meta era garantizar la unidad del ex reino de Guatemala como "un solo cuerpo, un solo estado, que aparece señalado por la naturaleza en la demarcación del continente septentrional". Una forma de aludir a la unidad geográfica que le daba el estar implantado en el istmo centroamericano y partiendo de la proposición de Del Castillo en las Cortes gaditanas de dividir a América en septentrión y meridiano.

En esa coyuntura de separación de la tutela española a raíz del Plan de Iguala, fue la Diputación Provincial de León, que incluía a Costa Rica, la que no se sumó a la propuesta. Al conocer la noticia de la declaración de Independencia del 15 de septiembre, su reacción fue emitir un Acta el 28 de ese mes y año indicando que no se sumaba a "la independencia del gobierno español hasta tanto no se aclaren los nublados del día y pueda obrar esta provincia con arreglo a lo que exigen los empeños religiosos y sus verdaderos intereses". ${ }^{25} \mathrm{De}$ esa manera, dejaba en claro que no deseaba seguir a las otras provincias del ex Reino $\mathrm{y}$, por tanto, no entraba en conflicto con España. Es decir, esperar a ver si no había una marcha atrás por un posible triunfo de las autoridades españolas y sus partidarios tanto en la Nueva España como en Guatemala. Finalmente, el 11 de octubre la Diputación leonesa proclamó su independencia absoluta de España, pero enseguida surgieron desavenencias en su territorio. Los Partidos de Granada y de Costa Rica erigieron gobiernos separados del de León, y el de Costa Rica reasumió 31 de octubre de 1821 la condición de provincia en la Constitución que emitió el $1^{\circ}$ de diciembre de 1821, denominada Pacto Social Fundamental

24 Manuel Benavides Barquero, "Las Cortes de Cádiz: eslabón perdido de la historiografia centroamericana" en Cuadernos Americanos No 155, México, 2018/4, pp. 11-42.

25 Montero Barrantes, Francisco, Elementos de la Historia de Costa Rica, San José, EUNED, 2006, Tomo I. 
Interino o Pacto Concordia, dándole plenos poderes de gobierno a la Junta de Legados reunida en la ciudad de Cartago.

Sin embargo, al final primaria la propuesta de Iturbide a Gainza de 19 de octubre planteando posibilidad de unión del antiguo Reino a México debido a ser "tan idéntico e indivisible, que no pueden erigirse en naciones separadas e independientes sin aventurar su existencia y seguridad."26 Gainza tardó en concretar tal propuesta a las juntas y diputaciones de las otras provincias centroamericanas. El 5 de enero de 1822, éste envió la misma a los ayuntamientos para que votasen por la unión a México. De estos, 147 lo hicieron por ella, 21 por lo que resultara del Congreso de las provincias que debía de reunirse el 1 de febrero de 1822 y 2 lo hicieron en contra. La idea principal de los defensores de la unión era que México podría resguardar militarmente el istmo, contribuir a financiar la Hacienda, mejorar el intercambio comercial y sus rutas $\mathrm{y}$, en gran medida, tener un árbitro frente al tradicional poder de la élite de la ciudad de Nueva Guatemala. En las provincias de San Salvador, Tegucigalpa, Nicaragua y Costa Rica surgieron grupos de opositores a tal unión, proclamando lo imperativa unidad del territorio guatemalteco y la necesidad de dotarlo de un sistema de gobierno republicano si quería insertarse en el concierto de las Naciones. La proclamación de Iturbide como emperador de México el 18 de mayo desbarató sus aspiraciones. Hubo que esperar dos años más para que el ex Reino declarase su Independencia absoluta e iniciase el proceso de convertirse en la República Federal del Centro de América. En la redacción de la Constitución Federal del 22 de noviembre de 1824 participaron un gran número de los politicos, administradores, profesionales y clérigos que vivieron en primera línea la coyuntura iniciada en Cádiz en 1810 y que produjo la Constitución gaditana dos años más tarde.

Enviado el (Submission Date): [29/04/2021]

Aceptado el (Acceptance Date): [Deje sin cubrir este extremo]

\section{BIBLIOGRAFIA}

"Acta de Independencia”, Memoria Centroamericana, Instituto de Historia de Nicaragua y Centroamérica, http://memoriacentroamericana.ihnca.edu.ni/uploads/media/Declaracion_de_indepe ndencia.pdf consultado 25 de abril de 2021.

Álvarez Sánchez, Adriana, "La Real Universidad de San Carlos de Guatemala frente al proceso de In- dependencia (1808-1815)", XIV Encuentro de Latinoamericanistas Españoles: congreso internacional, Santiago de Compostela, España. Septiembre de 2010, pp.489-508.

Apuntamientos sobre la Agricultura y Comercio del Reyno de Guatemala que el Señor Dr. Don Antonio Larrazabal Diputado en las Cortes Extraordinarias de la Nación por las

26 Miles Wortman, "Legitimidad política y regionalismo. El Imperio mexicano y Centroamérica" en Historia mexicana, Vol. 26/2, México, 1976, p. 245. 
misma Ciudad pidió al Real Consulado en Junta de Gobierno de 20 de Octubre de 1810 Nueva Guatemala. Impreso en la Oficina de D. Manuel de Arévalo. Año de 1811.

Apuntes Instructivos que al Señor Don Antonio Larrazabal DIPUTADO a las Cortes Extraordinarias de la Nación Española por el Cabildo de la Ciudad de Guatemala dieron sus regidores Don José de Isasi, Don Sebastián Melón, Don Manuel González y Don Juan Antonio de Aqueche. NUEVA GUATEMALA Impreso en la Oficina de D. Manuel de Arévalo. Año de 1811.

Avendaño Rojas, Xiomara, "El Gobierno provincial en el reino de Guatemala, 18211823", Históricas digital, México, UNAM/Instituto de Investigaciones Históricas, 29 de junio de 2018, pp. 321-354.

Avendaño Rojas, Xiomara, "Los escenarios del poder en 1821: la juramentación del Acta de la Independencia en la provincia de Guatemala" Aaron Pollack (coordinador), La época de las independencias en Centroamérica y Chiapas. Procesos politicos y sociales. México, Instituto Mora/ UAM Iztapalapa, 2013, pp. 225-250.

Avendaño Rojas, Xiomara, Centroamérica entre lo antiguo y lo moderno. Institucionalidad, ciudadania y representación política, 1810-1838. Castelló, Universitat Jaume I, 2009.

Benavides Barquero, Manuel, "Las Cortes de Cádiz: eslabón perdido de la historiografia centroamericana", Cuadernos Americanos No 155, México, 2018/4, pp. 11-42.

Benavides Barquero, Manuel, "Las Cortes de Cádiz: eslabón perdido de la historiografia centroamericana” en Cuadernos Americanos No 155, México, 2018/4, pp. 11-42.

Benavides Barquero, Manuel, El presbitero Florencio del Castillo. Diputado por Costa Rica en las Cortes de Cádiz, San José de Costa Rica, Editorial LIL, 2010.

Bonilla Bonilla, Adolfo, “The Central American Enlightenment, 1770-1838: An Interpretation of Political Ideas and Political History", Tesis de doctorado, Universidad de Manchester, 1996.

Brañas, César, José Antonio de Larrazábal, un guatemalteco en la historia, Guatemala, Editorial Universitaria, 1969.

Chust, Manuel, La cuestión nacional americana en las cortes de Cádiz (18101814), Valencia, Artes Gráficas Soler, 1999.

Díaz Arias, David y Rony Viales Hurtado (recopiladores), Independencia, estados y Politica(s) en la Centroamérica del siglo XIX: las huellas del bicentenario, San José, Centro de Investigaciones Históricas de América Central-UCR, 2012.

Discurso pronunciado por el señor D. Francisco de Paula Vilches Regente de esta Real Audiencia Territorial, el día 24 de julio, en el acto de instalación del Tribunal en el sistema de la Constitución y la ley de 9 de octubre. Guatemala: Oficina de Ignacio Beteta.

Dym, Jordana, "Our Pueblos, Fractions with No Central Unity": Municipal Sovereignty in Central America, 1808-1821", Hispanic American Historical Review 86 (3), Duke University Press, 2006, pp. 431-466.

Dym, Jordana, "Soberanía transitiva y adhesión condicional: lealtad e insurrección en el Reino de Guatemala, 1808-1811", Araucaria: Revista Iberoamericana de Filosofia, Politica, Humanidades y Relaciones Internacionales, Vol. 9, № 18, 2007, págs. 196-219 
Dym, Jordana, "Soberanía transitiva y adhesión condicional: lealtad e insurrección en el reino de Guatemala, 1808-1811", Revista Iberoamericana de Filosofía y Humanidades, $N^{\circ}$ 18, Segundo semestre, Universidad de Sevilla, 2007, pp. 196-219.

Escritos del Doctor Pedro Molina, El Editor Constitucional. III Tomos, Guatemala, Ministerio de Educación Pública, 1954.

Escritos del licenciado José Cecilio del Valle. El Amigo de la Patria, II Tomos, Guatemala, Editorial José Pineda Ibarra, 1969.

García Laguardia, Jorge Mario, Centroamérica en las Cortes de Cádiz, México, Fondo de cultura Económica, 1994

Garcia Laguardia, Jorge Mario, Génesis del Constitucionalismo guatemalteco, Guatemala, Editorial Universitaria, 1971.

Instrucciones para la constitución fundamental de la Monarquía Española y su Gobierno de que ha de tratarse en las próximas cortes generales de la Nación Dadas por el M. I. Ayuntamiento de la M. N. y L. Ciudad de Guatemala a su Diputado el Sr. D. Antonio Larrazabal Canónigo Penitenciario de esta Sta. Iglesia metropolitana formadas por el Sr. José María Peinado, regidos perpetuo y decano del mismo Ayuntamiento. Las da a luz en la ciudad de Cádiz el referido diputado. En la Imprenta de la Junta Superior. Año de 1811.

"Instrucciones para la Constitución Fundamental de la Monarquía Española y su Gobierno de que ha de tratarse en las próximas cortes generales de la Nación", en García Laguardia, Génesis del Constitucionalismo guatemalteco, Guatemala, Editorial Universitaria, 1971, pp. 112-113.

Jovel, J. Roberto, Medallas de proclama de los reyes de España usadas como monedas en Centroamérica, San Salvador, Imprenta y Offset Ricaldone, 2013, pp. 127-135.

Montero Barrantes, Francisco, Elementos de la Historia de Costa Rica, San José, EUNED, 2006, Tomo I.

Pollack, Aaron, "Totonicapán, 1820: ¿una de las puntas del iceberg? en Aaron Pollack (coordinador), La época de las independencias en Centroamérica y Chiapas. Procesos politicos y sociales. México, Instituto Mora-UAM Iztapalapa, 2013, pp. 189-224.

Recopilación de documentos históricos desde la fundación de la Nueva Guatemala en 1776 hasta el año de 1865. Opúsculo Número 4, Guatemala, Diario de Centro América, 1930.

Rodríguez, Mario El experimento de Cádiz en Centroamérica, 1808-1826, México, Fondo de cultura Económica, 1984

Taracena Arriola, Arturo, "Manuel Del Llano", "Andrés del Llano" en Diccionario Biográfico de Parlamentarios Españoles, 1820-1854, Madrid, Cortes Generales, 2012-2013. (CD).

Taracena Arriola, Arturo, "Mariano Córdova", "José María Álvarez", Andrés del Llano" en Diccionario Biográfico de Parlamentarios Españoles, 1820-1854), Madrid, Cortes Generales, 2012-2013. (CD) 
Taracena Arriola, Arturo, "Nación y República en Centroamérica (1821-1865)", Taracena Arriola, Arturo y Jean Piel (compiladores, San José de costa Rica, Editorial Universitaria de Costa Rica, 1995, pp. 45-61.

Taracena Arriola, Arturo, y at. lat. Etnicidad, Estado y nación en Guatemala, 18081944. Vol. 1. Guatemala, CIRMA, 2002.

Taracena Arriola, Luis Pedro, "Mateo Ybarra”, “José Mariano Méndez Cordero" en Diccionario Biográfico de Parlamentarios Españoles, 1820-1854), Madrid, Cortes Generales, 2012-2013. (CD).

Timothy Hawkins, José de Bustamante and Central American independence:colonial administration in an age of imperial crisis, Tuscaloosa, University of Alabama Press, 2004.

Vázquez Olivera, Mario, "El Plan de Iguala y la independencia guatemalteca", Históricas digital, México, UNAM/Instituto de Investigaciones Históricas, 29 de junio de 2018, pp. 385-422.

Vázquez Olivera, Mario, "Centroamérica en la senda de Cádiz, 1820-1823", en Manuel Chust (ed.) iMueran las cadenas! El trienio liberal en América (1820-1824), Granada, Editorial Comares, pp. 77-113.

Wortman, Miles, "Legitimidad política y regionalismo. El Imperio mexicano y Centroamérica" en Historia mexicana, Vol. 26/2, México, 1976, p. 245.

Fecha de envío / Submission date: 23/04/2021

Fecha de recepción / Acceptance date: 6/05/2021 